\title{
STATUS HUKUM TERTIB DALAM RUKUN DUA KHUTBAH JUM’AT (TELAAH KRITIS FIQIH KLASIK)
}

\author{
Multazim AA. \\ IAI Ibrahimy Genteng Banyuwangi \\ Email: multazimaa@gmail.com
}

\begin{abstract}
Friday prayers are the provisions of Allah and His messengers to be performed by all Muslims whose legal status is fardlu ain yaikni must be done by every male, adult, independent and settled in an area (mukim), not mandatory for Muslim women, children children, slaves and people who are traveling (traveler). Friday Prayers are performed in a certain way and are only considered valid if they meet the requirements and harmony. One of the legal requirements for Friday prayers must be preceded by two Friday sermons. These two sermons can also be considered valid if they meet the requirements and get along well. The pillars of two popular sermons practiced in the midst of society are reading hamdalah, blessings on the Prophet Muhammad, willing the piety to Allah $S W T$, reading one verse in one of two sermons, and praying for Muslims and Muslims in the second sermon. These five things are read in an orderly manner even the implementation was carried out in an orderly manner, whereas, none of the verses of the Qur'an or al-Hadith that explains directly that the implementation of the two pillars of the sermon must be carried out in an orderly manner. That is why there is a need for a positive and more problematic answer for the people regarding the legal status of order in the two sermon harmony.
\end{abstract}

Keywords: Orderly, Pillars Two Prayer Friday

\begin{abstract}
ABSTRAK
Shalat jum'at merupakan ketentuan Allah dan rasul-Nya untuk dilakukan segenap ummat Islam yang status hukumnya fardlu ain yaikni wajib dilakukan oleh setiap ummat lakilaki, dewasa, merdeka dan menetap dalam suatu daerah (mukim), tidak wajib dilakukan muslimah, anak-anak, hamba sahaya dan orang yang sedang bepergian (Musafir). Shalat Jum'at dilakukan dengan cara tertentu dan baru dianggap sah apabila memenuhi syarat dan rukun. Salah satu syarat sah shalat Jum'at tersebut antara lain harus didahului dua khutbah jum'at. Dua khutbah tersebut juga bisa dianggap sah apabila memenuhi syarat dan rukun. Adapun rukun dua khutbah yang popular di praktekkan ditengah masyarakat adalah membaca hamdalah, shalawat atas Nabi Muhammad SAW, berwasiat takwa kepada Allah $S W T$, membaca satu ayat pada salah satu dari dua khutbah, dan mendoakan kaum muslimin dan muslimat pada khutbah kedua. Lima hal tersebut pembacaannya secara tertib bahkan pelaksanaanya pun dillakukan secara tertib, padahal, tak satupun ayat al-Qur'an atau al-Hadist yang menjelaskan secara langsung bahwa pelaksanaan rukun dua khutbah harus dilakukan secara tertib. Karena itulah perlu adanya jawaban yang positif dan lebih maslahah buat umat mengenai status hukum tertib dalam rukun dua khutbah.
\end{abstract}

Kata kunci: Tertib, Rukun Dua Khutbah Jum'at

\section{PENDAHULUAN}

Syariat Islam dalam rentetan sejarah turunnya merupakan syariat yang terakhir diturunkan Allah SWT, maka sesuai dengan kedudukan ini Syariat Islam mempunyai 
keistimewaan disbanding dengan syariat sebelumnya. Keistemewaan inilah yang memberikan corak dan bentuk kepada syariat Islam berbeda dengan syariat sebelumnya. Keistimewaan tersebut antara lain pertama misinya bersifat universal, yakni berbentuk dan bercorak syariat yang tidak hanya untuk masyarakat dan bangsa tertentu tetapi unuk umat manusia seluruhnya, untuk sepanjang zaman, sejak diturunkan sampai hari kiamat, untuk bangsa Arab dan 'Ajam. Kedua, bersifat integral, yakni tidak hanya mengatur ibadah secara formal saja, tetapi mencakup seluruh aspek kehidupan. Ketiga, bersifat global, yakni berlaku mutlak bagi semua umat manusia sepanjang masa, sedangkan tiaptiap bangsa atau generasi mempunyai kekhususan-kekhususan. Hal ini dimaksudkan agar syariat tetap dapat dipergunakan untuk mengatur bangsa dan generasi yang berbeda.

Diantara syariat yang ditetapkan Allah dan Rasul-nya adalah shalat Jum'at, yang status hukumnya fardlu ain yakni wajib dilakukan oleh setiap individu yang muslim, berakal, baligh, laki-laki, merdeka, sehat dan menetap dalam suatu daerah (mukim). Shalat Jum'at baru dianggap sah apabila memenuhi syarat dan rukun, yang salah sat unya adalah harus didahului oleh dua khutbah. Demikian pula, dua khutbah tersebut baru dianggap sah, apabila memenuhi syarat dan rukun. Rukun dua khutbah jum'at yang sudah popular dikalangan Ulama ada lima, yaitu membaca hamdalah, shalawat atas Nabi Muhammad SAW, berwasiat unt uk bertakwa kepada Allah SWT, membaca satu ayat alQur'an pada salah satu dua khutbah, dan mendoakan terhadap segenap kaum muslimin dan muslimat pada khutbah kedua. Rukun dua khutbah tersebut didalam kitab-kitab klasik penuturannya disebutkan secara tertib, demikian pula, pelaksanaannya juga secara tertib. Padahal, tidak ada dalil satupun, baik al-Qur'an dan al-Hadist yang memerintahkan secara tegas agar rukun dua khutbah tersebut dilakukan secara tertib, sehingga timbul sebuah rumusan masalah, bagaimana status hukum tertib dalam dua khutbah jum'at yang tentunya memerlukan jawaban yang positif, manfaat dan maslahat buat segenap umat Islam.

\section{PENGERTIAN SHALAT JUM'AT}

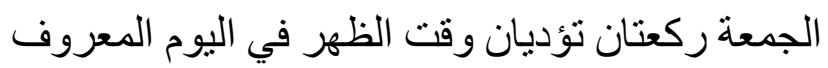

Shalat Jum'at adalah shalat dua rakaat yang dilakukan diwaktu dluhur dihari tertentu. (Ahmad bin Umar al-Syathiry, TT: 50). 
Shalat Jum'at merupakan shalat yang berdiri sendiri, bukannya shalat dluhur yang diringankan menjadi dua rakaat, ia seperti shalat lainnya, baik dari segi rukun, syarat dan tata caranya.

\section{HUKUM SHALAT JUM'AT}

Hukumnya fardlu ain. Hal ini berdasarkan firman Allah SWT dalam al-Quran surah Al-Jumuah ayat 9:

Artinya: "Hai orang-orang yang beriman, apabila diseru untuk menunaikan sembahyang pada hari Jum'at maka bersegeralah kamu kepada mengingat Allah dan tinggalkanlah jual beli"(Al-Qur'an Depag RI, 1986:933)

Yang dimaksud dengan mengingat Allah SWT dalam ayat tersebut, secara majas adalah sembahyang, ada pula khutbah, maka Allah memerintahkan untuk bersegera mengingat Allah SWT, yang menurut dlahirnya ayat adalah wajib, apabila segera itu wajib, maka apa yang menjadi tujuan kesegeraan itu juga wajib, dan Allah SWT melarang jual beli yang hukumnya boleh, Allah tidak melarang perbuatan yang diperbolehkan kecuali karena melakukan perbuatan wajib.

Shalat Jum'at yang dihukumnya fardlu ain tersebut, apabila terpenuhi syaratsyaratnya, yaitu: laki-laki, merdeka, sehat, dan bertempat tinggal dalam suatu daerah (Abu Bakar, TT:52). Juga karena ada sabda Nabi Muhammad SAW riwayat Abu Dawud dan Hakim, yang artinya: “Jum’at itu hak yang wajib dikerjakan oleh setiap orang islam dengan berjamaah, kecuali empat macam orang, yaitu: hamba sahaya, perempuan, anakanak, dan orang yang sakit”. (Sulaiman Rasyid, 1989:124).

Shalat Jum'at diwajibkan di Makkah pada malam Isra', namun pendapat ini ditentang oleh Ibnu Hajar, karena beberapa hadis shahih menunjukkan bahwa shalat Jum'at itu diwajibkan di Madinah, dengan arti kewajiban shalat Jum'at ditetapkan wajibnya di Madinah, lantaran hilangnya udhur yang beliau lakukan bersama Sahabat, yaitu belum terpenuhinya syarat Jum'at.

Adapun orang yang pertama melakukan shalat jum'at di Madinah sebelum Nabi hijrah adalah As'ad bin Zurarah di suatu desa yang jauhnya satu mil dari Madinah. Dinamakan Jum'at lantaran manusia pada waktu itu berkumpul untuk melaksanakan Shalat atau karena Nabi Adam berkumpul dengan Hawa di Muzdalifah pada hari Jum'at (Abu Bakar, TT: 52-53) 


\section{SYARAT SAH JUM'AT}

Shalat Jum'at dikatakan sah apabila memenuhi syarat, yaitu:

1. Shalat Jum'at dan kedua Khutbahnya dilaksanakan di waktu Dluhur, jika wakt unya sempit, maka melakukan takbiratul ihram dengan melaksanakan shalat Dluhur. Jika waktu sudah habis sedangkan masih dalam shalat Jum'at, maka harus menyempurnakan shalat dluhur tanpa memperbarui niat.

2. Diadakan di suatu negeri, yakni tempat melaksanakan shalat Jum'at atau di tempat dimana orang yang hendak bepergian tidak boleh mengqosor shalat disitu.

3. Rakaat pertama dari dua rakaat tersebut dilakukan secara berjamaah, apabila ada yang niat mufaraqah (berpisah dari Imam) pada rakaat yang kedua, lalu menyempurnakan shalatnya sendirian, maka shalat Jum'ah tersebut tetap sah.

4. Orang yang ikut shalat Jum'at sebanyak 40 orang yang menetap dalam suatu negeri yang berkewajiban melakukan shalat Jum'at, yang tidak bepergian dari tempat tinggalnya, baik dimusim dingin maupun musim panas, kecuali ada keperluan seperti berdagang atau ziarah.

5. Tidak didahului atau dibarengi oleh shalat Jum'at lain di negeri Jum'at itu. Apabila didahului oleh shalat Jum'at lain, maka yang mendahului itulah yang dianggap sah. Jika keduanya berbarengan maka keduanya tidak sah(batal). Yang demikian ini apabila tidak ada kesulitan untuk berkumpul menjadi satu. Apabila terdapat kesulitan seperti tempatnya tidak dapat menampung orang yang melakukan shalat Jum'at, atau jauh dari tempat jum'at atau karena terdapat peperangan, maka boleh shalat Jum'at dilakukan di beberapa tempat, sesuai dengan kebutuhan. Apabila ragu, apakah ia tergolong jamaah jum'at awal atau yang akhir, atau adanya bilangan pelaksanaan shalat Jum'at, karena suatu kebutuhan atau tidak, maka baginya wajib I'adah (Shalat dluhur atau jika memungkinkan shalat Jum'at. Jika tidak maka wajib shalat Dluhur saja).

6. Didahului oleh dua khutbah. (Ahmad bin Umar al-Syathiry, TT:5).

\section{PENGERTIAN KHUTBAH JUM'AT}

Khutbah berarti pidato atau uacapan-ucapan nasehat atau ucapan sebagai nasehat. Sedangkan khatib adalah orang yang berkhutbah, orang yang bertindak sebagai juru bicara. (M. Hasbi al-Shiddiqy,1989:213). 
Sedangkan Jum'at adalah nama hari yang ketujuh dari seminggu (M Hasbi alShiddiqy, 1989:211). Jadi khutbah Jum'at berarti pidato atau ucapan yang mengandung nasehat yang disampaikan oleh seorang khatib dihari Jum'at dengan cara tertentu (syarat dan rukunnya).

Ada yang mengatakan khutbah Jum'at adalah suatu tata cara yang merupakan sebagian dari pelakasanaan ibadah shalat Jum'at dengan disertai syarat dan rukun (Djafar Amir, 1985:5). Jelasnya, khutbah jum'at adalah pidato atau ucapan yang mengandung nasehat yang disampaikan oleh seorang khatib dihari Jum'at dengan cara tertentu yang merupakan sebagian dari pelaksanaan ibadah shalat Jum'at.

\section{DASAR HUKUM KHUTBAH JUM'AT}

Mayoritas Ilmuan berpendapat bahwa khutbah Jum'at adalah wajib. Mereka bepegang kepada hadits-hadits shahih yang menyatakan bahwa Nabi Muhammad SAW. Setiap mengerjakan shalat Jum'at selalu disertai khutbah (Sayyid Sabiq, 1999:221).

Salah satu hadits shahih tersebut antara lain:

عن نافع عن إبن عمر قال: كان رسول الله صلى الله عليه و سلم يخطب يوم الجمعة قائما ثم يجلس ثم يقوم :قال كما بفعلون اليوم

Artinya: dari Nafi' dari Ibnu Umar beliau berkata: adalah Rasulullah $S A W$ berkhutbah dihari Jum'at sambil berdiri, kemudian duduk, kemudian berdiri kembali. Ia berkata: "sebagaimana orang-orang lakukan sekarang ini” (Muslim, $T T: 342)$.

\section{SYARAT DUA KHUTBAH}


Artinya: Syarat adalah apa saja yang menjadikan sahnya sesuatu dan ia tidak termasuk bagian darinya. Seperti air mutlak merupakan syarat buat wudlu dan menutup aurat merupakan syarat buat shalat (Abdul Hamid Halim,1927:8)

Adapun syarat-syarat khutbah itu ada tiga belas:

1. Dilakukan oleh seorang laki-laki, tidak sah khutbah dilakukan oleh seorang wanita. 
2. Mendengarkan khutbah. Menurut Imam Ibnu Hajar, mendengarkan khutbah harus dengan perbuatan (bil fi'li) artinya suara khatib benar-benar sampai kepada pendengar. Sedangkan menurut Imam Romli, mendengarkan khutbah cukup dengan kekuatan (bil quwwah) artinya sekiranya pendengar mau mendengarkan khutbah, maka ia dapat mendengarnya.

3. Dilakukan di dalam batas bangunan masjid, yakni seorang khatib berada di dalamnya. Sedangkan selain khotib boleh berada diluarnya.

4. Khatib harus suci dari hadats. Yakni hadats besar maupun hadats kecil. Apabila terlanjur hadats maka harus bersuci dan memulai khutbah lagi dari awal, sekalipun dengan senggang waktu yang tidak lama.

5. Khatib harus suci dari najis, baik badan, pakaian maupun tempatnya.

6. Khatib harus menutup aurat.

7. Khatib harus berdiri jika mampu, jika tidak mampu maka boleh dengan duduk, jika masih tidak mampu maka boleh dengan berbaring. Namun yang lebih utama dicarikan pengganti.

8. Khatib harus duduk diantara dua khutbah, dengan ukuran tuma'ninah diwaktu shalat. Tanpa tuma'ninah menurut madzhab Syafi'i dianggap tidak sah. Sedangkan menurut lainnya dianggap sah. (al-Bakry,TT:76). Adapun yang lebih sempurna adalah dengan ukuran membaca surat al-Ikhlas, memang disaat itulah sunnah membaca surat ikhlas.

Adapun membaca shalawat diantara dua khutbah, dengan suara nyaring sebagaimana yang dilakukan bilal, adalah bid'ah hasanah dan dapat memutuskan muwalah apabila membacanya terhitung panjang menurut umum yakni diperkirakan waktunya cukup untuk shalat dua rakaat. Demikian keterangan dari kitab Kurdi, bab sunat-sunat Jum'at. (M. Nawawi Sarmidy, 1982:6).

9. Muwalah (bertubi-tubi) diantara dua khutbah yakni antara rukun yang satu dengan yang lain tidak terpisah oleh hal-hal yang tidak ada hubungannya dengan kedua khutbah artinya tidak terpisah oleh waktu yang cukup untuk shalat dua rakaat yang dilaksanakan dengan secepat mungkin. 
10. Muwalah (bertubi-tubi) antara dua khutbah dan shalat jum'at artinya takbirotul ihram shalat jum'at dan selesainya khutbah kedua tidak terpisah oleh waktu yang cukup untuk shalat dua rakaat yang dilakukan dengan secepat mungkin. Adapun shalat Jum'at dan khutbah, yang antara keduanya diselingi pembicaraan adalah sah apabila hanya sebentar (tidak cukup untuk shalat dua rakaat). (Al-Bakry,TT:70).

11. Dua khutbah tersebut menggunakan bahasa Arab sekalipun khatib dan para pendengarnya tidak faham. Adapun menterjemahkan khutbah selain rukun asalkan tidak panjang dan tidak keluar dari Mauidloh, maka tidak ada perselisihan di kalangan Imam Syafi'i tentang kebolehannya. Demikian keterangan dalam kitab Tuhfatul Muhtaj Juz 7 halaman 9 (M. Nawawi Sarmidy, 1982:148)

12. Dua khutbah tersebut terdengar oleh 40 orang yang menjadikan sahnya shalat Jum'at, karena itulah khatib harus mengeraskan suaranya sehingga mereka mendengarnya dengan perbuatan (bil fi'li) menurut Ibnu Hajar, kedua khutbah belum dianggap sah jika berbarengan dengan bising, gaduh/hiruk pikuk yang dapat mengganggu terdengarnya rukun dalam dua khutbah. Namun menurut Imam Romli tetap sah. Adapun khutbah menggunakan pengeras suara hukumnya sah. Demikian keterangan dalam kitab Bujayrimi 'ala al-Minhaj Juz 1 hal 390 (PP. Al-Anwar, 1991: 83).

13. Dua khutbah tersebut dilaksanakan pada waktu Dluhur. (Ahmad bin Umar al-Syathury, 1368:52).

\section{RUKUN DUA KHUTBAH}

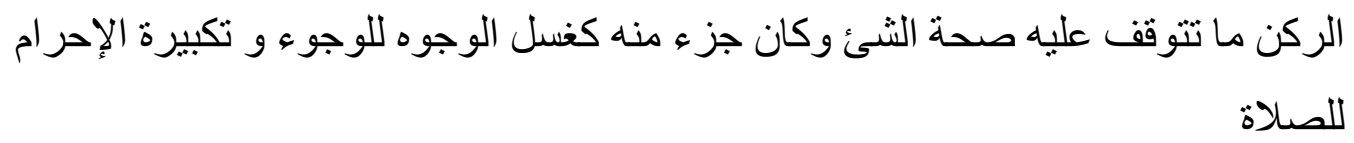

Rukun adalah apa saja yang menjadikan sahnya sesuatu dan ia termasuk bagian darinya. Seperti membasuh wajah untuk wudlu dan takbiratul ihram unt uk shalat (Abdul Hamid Hakim, 1929:7).

Adapun rukun dua khutbah adalah sebagai berikut: 
1. Mengucapkan puji-pujian kepada Allah SWT. Pada kedua khutbah. Hal ini berdasarkan sebuah hadits:

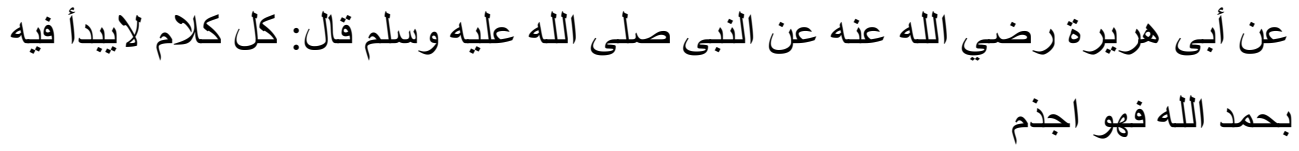

Artinya: Dari Abu Hurairah R.A. dari Nabi Muhammad $S A W$ bersabda: Setiap pembicaraan yang tidak dimulai dengan hamdalah (memuji Allah) maka ia bagaikan binatang yang terkena penyakit kusta(H.R. Abu Dawud). (Jalaluddin as-Suyuthy, 1954:94).

Sedangkan mengulang bacaan hamdalah itu, sama dengan mengulangi rukun khutbah, yang hukumnya adalah boleh (Abdur Rahman, 1955:82).

2. Membaca shalawat dan salam atas Nabi Muhammad SAW beserta keluarganya dan shahabatnya pada dua khutbah. Bacaan shalawat tersebut tidak cukup dengan menggunakan dlamir (kata ganti) (Zainuddin alMalibary, TT:43). Lebih sempurna lagi apabila disertai dua kalimat syahadat. Hal ini berdasarkan sebuah hadits:

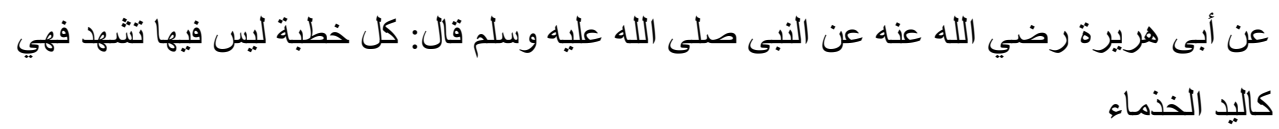

Artinya: Dari Abu Hurairah RA dari Nabi Muhammad SAW bersabda: Setiap khutbah yang di dalamnya tidak ada Tasyahud, maka ia seperti tangan yang terpotong (HR. Abu Dawud) (Jalaluddin al-Suyuthi, 1994:94).

Adapun membaca shalawat sewaktu khatib menyebut nama Rasulullah dengan suara keras, itu hukumnya sunnah, asal tidak keterlaluan. Demikian pula membaca taradli (Radliyallahu'anhu) sewaktu khatib menyebut nama sahabat. Apabila keterlaluan maka hukumnya haram (Al-Bakry, TT:67).

3. Berwasiat dengan kata-kata yang isinya menyeru untuk bertakwa kepada Allah SWT. Seperti kata-kata (اوصيكم بتقوى الله) atau (أطيعو الله ) yakni semua kata yang didalamnya terdapat seruan untuk taat kepada Allah SWT dan melarang berbuat maksiat kepada-nya.

Adapun membaca insyaallah ketika khatib menyerukan takwa kepada Allah SWT. Seperti kata-kata (اوصيكم بتقوى الله) itu hukumnya boleh asal tidak bermaksud menggantungkan takwa kepada kehendak Allah, sebab yang 
demikian itu berlaku terhadap apa yang akan dikerjakan (M.Nawawi Sarmidi, 1982:9)

4. Membaca satu ayat al-Qur'an yang dapat dipaham pada salah satu dua khutbah. Adapun yang lebih utama dibaca pada akhir khutbah pertama. Setiap membaca ayat al-Qur'an jangan lupa membaca ta'awudz. Allah SWT telah berfirman dalam surah An-Nahl:

Artinya: "apabila kamu membaca Al Quran hendaklah kamu meminta perlindungan kepada Allah dari syaitan yang terkutuk” QS.An-Nahl: 98 (Depag RI, 1986:417).

5. Mendoakan kaum muslimin atau mukminin pada khutbah kedua dengan doa yang berkenaan dengan akhirat (Muhammad bin Umar al-Syatiry, 1368:52).

\section{SUNNAH SUNNAH KHUTBAH}

Adapun sunnah-sunnah yang berkaitan dengan khutbah antara lain:

1. Hendaklah khutbah dilakukan di atas mimbar, atau di tempat yang lebih tinggi, terdiri dari tiga tangga, posisinya di sebelah kanan pengimaman. Adapun khutbah tanpa memegang tongkat itu khilaful aula (meninggalkan hal yang lebih utama).

2. Khatib hendaknya memberi salam.

3. Khatib hendaknya duduk di atas mimbar setelah memberi salam dan setelah duduk, itulah adzan dilakukan.

4. Khutbah diucapkan dengan kalimat yang fasih, terang, mudah difahami, sederhana (tidak terlalu panjang dan tidak terlalu pendek). Hal ini sesuai dengan sebuah hadits:

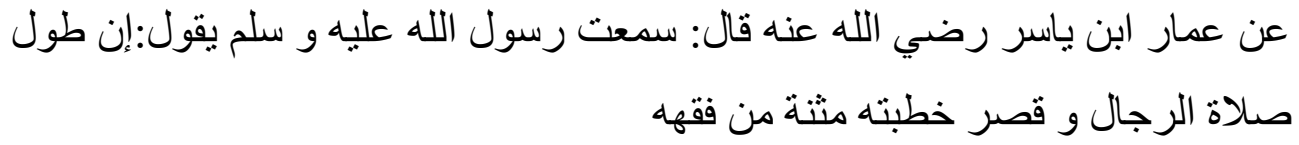

Dari Amr bin Yasir RA bekata: Aku telah mendengar Rasulullah $S A W$ bersabda: Sesungguhnya lamanya shalat seseorang dan pendeknya khutbah adalah suatu pertanda dalamnya pemahaman (HR. Muslim).

5. Khatib hendaklah tetap menghadap orang banyak, jangan berputar-putar karena yang demikian itu tidak disyariatkan. 
6. Mentertibkan tiga rukun yaitu dimulai dari puji-pujian, kemudian shalawat Nabi, kemudian berwasiat. Selain itu tidak ada tertib.

7. Membaca surat al-Ikhlas sewaktu duduk diantara dua khutbah.

8. Pendengar hendaknya diam serta memperhatikan khutbah. Kebanyakan Ulama' menyatakan Haram bercakap-cakap ketika mendengarkan khutbah (Sulaiman Rasyid, 1989:128).

Adapun sibuk menulis keterangan khutbah ketika khutbah sedang dibaca adalah haram jika menulisnya di luar tempat jum'at seperti di belakang masjid. Apabila menulisnya di dalam masjid maka hukumnya boleh. Demikian keterangan dalam kitab Bujairamy 1 hal 403 (M Nawawi Sarmidi, 1982:245).

\section{STATUS HUKUM MENTERTIBKAN RUKUN}

Ulama belum sepakat tentang status hukum mentertibkan rukun dalam khutbah Jum'at.

$$
\text { الترنيب هو وضع كل شئ في مرنبته و محله }
$$

Tertib adalah meletakkan segala sesuatu pada susunan dan tempatnya (Abu Bakar, TT:42).

Perbedaan pendapat ini bisa dilihat dalam Hasyiyah I'anatut Thalibin juz 2 halaman 66, yang redaksinya sebagai berikut:

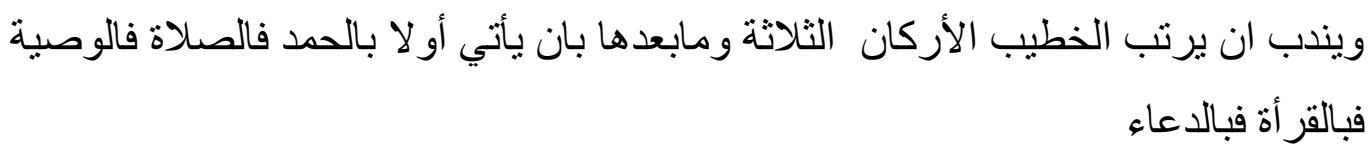

Disunnahkan khatib mentertibkan tiga rukun khutbah dan rukun setelahnya seperti pertama membaca hamdalah, shalawat atas Nabi SAW, berwasiat takut kepada Allah SWT, membaca ayat al-Qur'an lantas mendoakan kaum muslimin (Zainuddin alMalibari,TT:66)

Berdasarkan redaksi diatas Zainuddin al-Malibari berpendapat bahwa, status hukum tertib dalam dua khutbah jum'at adalah Sunnat, beliau beralasan sebagai berikut:



Sesungguhnya tertib dalam rukun khutbah Jum'at itu tidak wajib karena berhasilnya maksud khutbah dengan tanpa tertib. 
Adapun menurut Imam Rofi'i dan Al-Mawardi status hukum tertib dalam rukun dua khutbah jum'at itu wajib, redaksinya sebagai berikut:

$$
\text { وقال بالوجوب الر افعى و الماوردي }
$$

Imam Rofi'i dan Al-Mawardi menetapkan wajibnya tertib dalam dua khutbah Jum'at dengan alasan huruf jer ba', yang terdapat pada lafadz بان يأتي diatas , menggambarkan adanya tertib (Al-Bakry,TT:66). Dengan demikian rukun dua khutbah jum'at harus dilakukan secara tertib sesuai dengan penyebutan diatas, yaitu membaca hamdalah, membaca shalawat Nabi , berwasiat untuk bertakwa kepada Allah, membaca ayat al-Qur'an dan mendoakan kaum muslimin, tidak boleh dilakukan secara acakacakan tanpa tertib.

Pendapat beliau ini dikuatkan oleh pendapat Sulaiman Rasyid, yang menyatakan bahwa tertib dalam dua khutbah itu wajib pada tiga hal saja yaitu membaca hamdalah, shalawat atas Nabi dan Wasiat selain itu tidak ada tertib (lihat fiqih Islam, hal 128, bab sunnah-sunnah khutbah).

\section{ANALISIS}

Dua khutbah Jum'at itu di syari'atkan untuk memberi tutur kata, peringatan dan seruan untuk takwa kepada Allah swt. Allah berfirman :

$$
\text { فاسعو ا الى ذكز الله وذروا البيع }
$$

Yang artinya: Maka bersegeralah kamu kepada mengingat Allah dan tinggalkanlah jual beli.

Mengenai khutbah Nabi saw. dijelaskan :

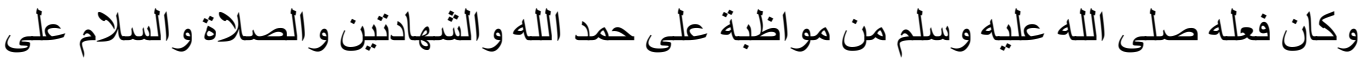
النبي و اله و الاتيان باما بعد و الحث على التقوى وقر اعة اية من القر أن في احدهما كل ذلك

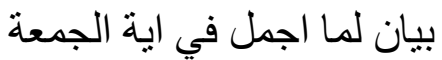

Perbuatan Nabi saw. Yakni kontinuitas beliau dalam memuji Allah, dua kalimat syahadat, shalawat dan salam atas nabi saw., beserta keluarganya dengan menggunakan ما بعد, seruan untuk bertakwa kepada Allah dan membaca satu ayat Al-Qur'an pada salah satu dari dua khutbah, kesemuanya itu sebagai 
penjelas terhadap ayat yang bersifat global yang terdapat pada surat Jum'at (Hasan Sulaiman An-Nury, 1969:77).

Redaksi di atas, memaparkan rukun khutbah satu demi satu menggunakan huruf athaf (kata penghubung) berupa wawu athaf yang menggambarkan tertib. Ini berarti rukun dua khutbah Jum'at harus tertib (berurutan) sesuai dengan yang dilakukan Rasulullah saw, bukan wawu athaf yang berfaedah muthlaqil jam'i (mutlaknya kumpul) yang memberikan pengertian asal semua dikerjakan maka dianggap sah. Sehubungan dengan segala urusan, lebih-lebih urusan agama, kita selaku umatnya disuruh mengikuti Nabi Muhammad saw. Hal ini sesuai dengan firman Allah swt. Surat Ali-Imran ayat 31 yang artinya : Katakanlah jika kamu benar-benar mencintai Allah, ikutilah aku niscaya Allah mengasihi dan mengampuni dosa-dosamu, Allah maha pengampun lagi maha penyayang (Depag RI, 1986:80).

Rasulullah saw. Bersabda :

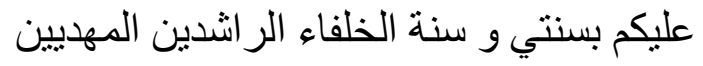

Artinya: Pegangilah sunnahku dan sunnah khulafaur rasyidin yang mendapat petunjuk.

Hadits ini memerintahkan kita umat Islam agar mengikuti Nabi saw dan khulafaur rasyidin, lebih-lebih urusan agama, termasuk praktek beliau dalam berkhutbah. Tanpa kita sadari ternyata khutbah beliau mencerminkan adanya tertib dalam rukun dua khutbah dan inilah yang diharapakan semua umat, baik urusan dunia maupun agama perlu adanya keteraturan, termasuk rukun dua khutbah Jum'at. Ali bin Abi Thalib berkata:

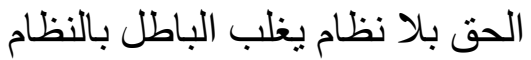

Yang artinya: Barang yang haq/ benar tanpa teratur/ terorganisir, akan dikalahkan barang batil yang terorganisir.

Rukun dua khutbah dengan menggunakan tertib seperti yang telah berlaku di masyarakat, berarti teratur dan terorganisir dimana hal ini akan lebih membawa maslahat dibandingkan yang tidak tertib akan terlihat acak-acakan. Allah SWT menghendaki kemaslahatan, sebagaimana yang Allah firmankan dalam Al-Qur'an surat Al-A'raf ayat 35 yang berbunyi: 
Artinya: Maka barang siapa yang bertakwa dan berbuat kebaikan tidaklah ada khawatir terhadap mereka dan tidak pula mereka bersedih hati (Al-A'raf : 35)

(Depag RI, 1986: 226).

Dari keterangan di atas, dapat disimpulkan bahwa rukun dua khutbah Jum'at dengan menggunakan tertib sebagaimana yang telah berjalan di tengah masyarakat akan lebih teratur dan lebih membawa maslahah umat, dibandingkan dengan yang tidak menggunakan tertib. Karena itulah tokoh agama dan pemimpin umat, untuk selalu berbuat dan bertindak, serta menerapkan yang lebih maslahah. Kaidah fiqih menjelaskan:

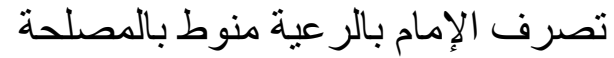

Perlakuan pemimpin terhadap rakyat disesuaikan dengan maslahat (Jalaluddin al-Suyuti, TT:181). Pemimpin disini termasuk pemimpin agama, pemimpin umat di tengah masyarakat harus bisa menyesuaikan serta mengambil kebijakan yang lebih baik dan lebih maslahah ditengah masyarakat, termasuk penerapan rukun dua khutbah Jum'at.

\section{PENUTUP}

Shalat jum'at merupakan kewajiban setiap umat Islam yang sudah memenuhi kriteria, dimana shalat Jum'at baru dianggap sah apabila menetapi syarat dan rukun , diantara salah satu syarat sahnya harus didahului dua khutbah, yang sudah barang tentu harus pula memenuhi syarat dan rukun. Agar khutbah bisa efektif, tentu perlu adanya khatib yang memenuhi kriteria dan para audien mendengarkan dengan penuh khidmat. Sehubungan dengan pokok pembahasan tentang status hukum tertib dalam rukun dua khutbah, ulama belum satu pendapat, ada yang menghukumi sunat dan ada yang menghukumi wajib. Setelah penulis analisa, berdasarkan al-Qur'an, al-Hadist, kaidah fiqih dan gramatika bahasa maka dari pemaparan diatas dapat disimpulkan bahwa status hukum tertib dalam dua khutbah Jum'at adalah wajib, inilah pendapat yang kuat dan lebih maslahat untuk diterapkan ditengah masyarakat.

\section{DAFTAR PUSTAKA}

Abdul Hamid Hakim, (1927) Mabadi’ Awwaliyah, Jakarta: Saadiyah Putra. 
Abu Bakar al-Misry, (TT), I'anatut Tholibin Juz 1, Bandung, Al-Ma'arif Ahmad al-Syatiry, (TT), Al-Yaqut an Nafis, Bairut, Darul Tsaqafah al-Islamiyah Departemen Agama RI (1986), Al-Qur'an dan terjemahnya, Jakarta: PT. Intermasa. Djafar Amin, (1985) Khutbah Jum'at, Bandung: PT. Al-Munif. Hasan Sulaiman an-Nury (1969), Ibanatul Ahkam, Surabaya: Al-Hidayah. Jalaluddin al-Mahally (1959), Mahally, Mesir: Mushodafa al-Baky, al-Halaby Jalaluddin al-Suyuthy (1954) Bughyatul Mustarsyidin, Mesir: Al-Dudy M Hasbi al-Shiddiq, (1989) Pengantar Hukum Fiqih, Jakarta: PT Bulan Bintang. M Nawawi (1982) Hidayatul Mubtadiin, Kediri: Fathul Ulum.

Muslim, (TT) Shoheh Muslim, Semarang: Dahlan.

PP. Al-Anwar, (1991) Tholi'atul Ahkam, Rembang:

Sulaiman Rasyid, (1989), Fiqih Islam, Bandung: Sinar Baru.

Zainuddin al-Malibary (TT), Fathul Mu'in, Bandung: Al-Ma'rif. 